\title{
Theorizing About Marriage
}

Jason S. Carroll

Brigham Young University - Provo, jcarroll@byu.edu

Stan J. Knapp

Brigham Young University - Provo

Thomas B. Holman

Brigham Young University - Provo

Follow this and additional works at: https://scholarsarchive.byu.edu/facpub

Part of the Other Social and Behavioral Sciences Commons

\section{Original Publication Citation}

Carroll, J. S., Knapp, S., \& Holman, T. B., (2005). Theorizing About Marriage. In V. L. Bengtson, A. C. Acock, K. R. Allen, P. Dilworth-Anderson, and D. M. Klein (Eds.). Sourcebook of Family Theory and Research. (pp. 263-288). Thousand Oaks, CA: SagePublications.

\section{BYU ScholarsArchive Citation}

Carroll, Jason S.; Knapp, Stan J.; and Holman, Thomas B., "Theorizing About Marriage" (2005). Faculty Publications. 4324.

https://scholarsarchive.byu.edu/facpub/4324

This Book Chapter is brought to you for free and open access by BYU ScholarsArchive. It has been accepted for inclusion in Faculty Publications by an authorized administrator of BYU ScholarsArchive. For more information, please contact ellen_amatangelo@byu.edu. 


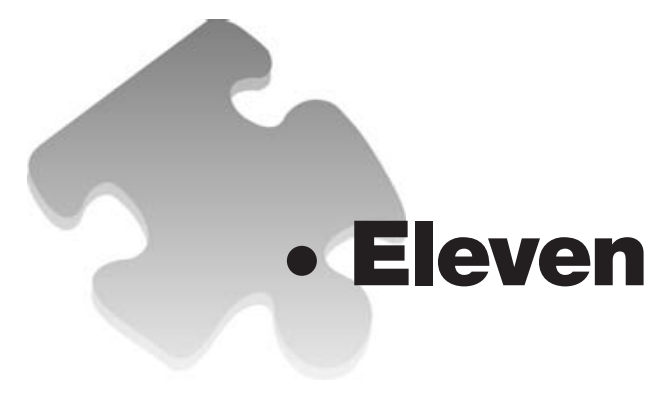

\title{
THEORIZING ABOUT MARRIAGE
}

\author{
Jason S. Carroll, Brigham Young University \\ Stan J. Knapp, Brigham Young University \\ Thomas B. Holman, Brigham Young University
}

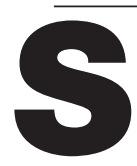

ince its inception in the 1920s, research on marriage relationships has attracted widespread attention within a variety of disciplines and has held a central position in the scientific study of families. However, despite marriage scholarship's long tradition and broad interdisciplinary base, a number of scholars believe that this area of research has reached a crossroads at the beginning of the 21 st century. This pivotal moment is seen as largely the result of a lack of explicit theory development in the marriage field. In fact, during the past decade several leading marriage scholars have called for the development of broad integrative frameworks to guide research and intervention efforts with married couples (Fincham \& Beach, 1999; Holman, 2001; Karney \& Bradbury, 1995).

In addition to calling for new theory development, some marriage scholars have also begun to question the dominant theoretical orientations and therapeutic assumptions of the marriage field (Browning, 2003; Cere, 2000; Doherty \& Carroll, 2002; Fowers, 2000; Knapp, 2002). In general terms, these scholars have identified the need for more explicit and rigorous dialogue about the implicit assumptions that underlie current conceptual and methodological approaches to the study of marriage.

In this chapter, we present a critical commentary on the current state of theorizing about marriage. Our primary argument is that the process of theorizing is important for high-quality, productive scholarship. The future vitality of marriage scholarship lies in the development of both theoretical frameworks that can integrate disparate lines of existing research and theoretical practices that can open up new areas of investigation. We argue that both integration and innovation require a deeper articulation and analysis of the ontological, epistemological, and evaluative assumptions that inform marital scholarship. We also assert that a more explicit focus on theory development in the marriage field will prompt marriage therapists and educators to examine more thoroughly the clinical assumptions that guide their work with premarital and marital couples, thereby leading to better fit among research, theory, and practice. 


\section{THEORIZING}

\section{(ABOUT MARRIAGE) IS CRUCIAL}

We agree with the editors of this volume when they suggest in Chapter 1 that theory is crucial, and we believe this is nowhere more true than in the study of marriage. We also believe that theorizing can take many forms, including formal model building and propositional theory development as well as paradigmatic critique of prevailing assumptions that undergird scholarly investigation. Our focus in this chapter is on the last of these forms of theorizing. We also agree with those who suggest that marital scholarship is at a crossroads and that continued progress in the field depends on improvements in the development and use of theory. The issues, then, are how we can be more theoretically minded and how we can move marital scholarship along through our theorizing.

The systems theory concept of levels or types of analysis is useful for organizing where we are and where we need to go in theorizing about marriage. Watzlawick, Weakland, and Fisch's (1974) metaphor of changing gears in an automobile with a standard transmission illustrates differing types of analysis. When one is driving a truck, for instance, engaging different gears allows one to produce different kinds of movement. Each gear is limited in the kind of movement it can produce: A low gear may enable more power, and a high gear may enable greater speed. Therefore, if the truck is in the right gear, improving speed or power may be simply a matter of stepping on the gas. However, there is a limit to the power or speed-or both—that the truck can achieve in any one gear. One gear is not necessarily superior to another, but neither is one gear alone sufficient. We increase our power, speed, and range by using multiple gears. Becoming more theoretically minded can be like "stepping on the gas" as we refine and expand existing conceptualizations. But it can also require that we "shift to alternative gears," because we may never get to all the important destinations we need to reach if we use only one of the gears available to us.

\section{THEORIZING ABOUT MARRIAGE} WITHIN THE RECEIVED VIEW

The "gear" currently in use in the study of marriage is grounded in what some have called the "received view" of scientific inquiry (Lincoln \& Guba, 2000; Thomas \& Wilcox, 1987). This view is similar to what the editors of this volume see as one of the "basic orientations" or overarching approaches to theorizing (see Chapter 1); we use the term received view to refer to the mainstream of sociological and psychological theorizing that has been and is being done about marriage. The underlying philosophical position of the received view is positivism (Thomas \& Wilcox, 1987), with its attendant ontological, epistemological, and methodological assumptions (Guba \& Lincoln, 1994; Lincoln \& Guba, 2000). The dominant application of this paradigm in the marriage field is witnessed in the widespread acceptance of a scientific approach that emphasizes "empirical theory," or the idea that descriptive research is objective in nature and, therefore, can and should precede theory in the scientific enterprise. Markman, Notarius, Stephen, and Smith (1981) articulate this paradigm when they state, "A solid data base is a prerequisite to theory development [and] can be best accomplished by descriptive studies which focus on observable behavior" (p. 236). At the core of this "empirical-descriptive" approach is the assumption that observable patterns of behavior can be understood in purely objective ways that will lead to universally accepted interpretations.

Grounded in the received view of scientific inquiry, the past 25 years of research on marriage has focused predominantly on observable patterns of interaction between spouses-particularly interactions around marital conflict (for a review, see Gottman \& Notarius, 2000). In general terms, this research has yielded an increased understanding of the "topography of marital conflict" (Fincham \& Beach, 1999, p. 49) through a focus on the delineation of sequential patterns of behavior that differentiate distressed marital couples from nondistressed marital 
couples (Bradbury, Fincham, \& Beach, 2000). Specifically, this line of research has shown that, compared with nondistressed couples, distressed couples are characterized by greater amounts of negativity, reciprocity of negative behavior, more sustained negative interaction, and escalation of negative interactions (Gottman \& Notarius, 2000). More recent studies in this line of research have focused on less immediately observable aspects of marital interaction, global patterns of interaction, and neglected prosocial dimensions of marital behavior (Bradbury et al., 2000).

\section{Limitations Within the Received View}

Although observational research on couple processes has generated rich descriptive accounts of marital interactions and identified a number of behavioral markers of marital distress, some limitations of this empirical-descriptive approach to studying and theorizing about marriage are beginning to emerge. In what follows, we briefly review five such limitations: (a) a lack of theorizing about data, (b) a lack of cross-fertilization of work from researchers with disparate (disciplinary) orientations, (c) a lack of integration and theory development, (d) a commitment to an atheoretical myth that limits rigorous examination of grounding assumptions, and (e) the production of empirical-descriptive work that can sometimes fail to provide full explanations of, and improved theoretical understanding for, the processes described.

Lack of theorizing about data. As in other aspects of family theorizing, theorizing about marriage within the received view suffers from work that is minimally "grounded" in theory, but when grounded, "the association between such theories and research tends to be loose and imprecise and, in some cases, constitutes only a metaphorical connection" (Fincham \& Beach, 1999, p. 55). What are sometimes called theories of marriage are often little more than "empirical generalizations" and do not fit the commonly accepted definitions of theory in terms of scope or level of abstraction.
Lack of cross-fertilization. A purely descriptive approach to research tends to discourage "cross-fertilization" of ideas among marriage scholars in different disciplines. One result of this insularity of research to disciplinary frameworks is that the collective knowledge base of marital studies becomes "scattered across a variety of disparate sources," making it difficult for anyone "to access the picture of marriage painted by scientific research" (Fincham, 1998, p. 543).

Lack of integration and theory development. The most central and perhaps most widely voiced criticism of current marital scholarship is the relative lack of development of broad theoretical frameworks to integrate research and clinical intervention (Fincham \& Beach, 1999; Karney \& Bradbury, 1995). In the past 30 years, marital research has generated a large number of theoretical constructs and midrange models that have proven valuable in helping scholars to understand the success and failure of marriage relationships. However, conceptual work in the marital domain has proceeded in an additive fashion rather than a cumulative one. For example, many current model-building efforts focus on widening the scope of inquiry in an effort to contextualize marital interactions. It appears that although a purely descriptive-empirical approach has proven useful in generating new conceptual ideas, it has been less successful in leading scholars to integrate and synthesize these ideas into integrated theories.

The atheoretical myth. As we have noted, many marital scholars working within the received view of scientific inquiry promote the belief that atheoretical observation is possible and desirable. This assumption limits the kind of theoretical analysis available to scholars and may prevent both theoretical awareness and progress. Theory is always in operation in our work, whether we acknowledge it or not. We concur with Fincham and Beach's (1999) assertion that fundamental to further progress is marital scholars' need to "make explicit and critically analyze the assumptions that 
informed the choice of what to observe in the first place” (p. 55).

Description without explanation. Perhaps most important is the argument that a purely behavioral account of marriage often leads to "progress" without improved understanding. Thus, although observational approaches may be productive of all kinds of empirical data and models, the data and models often remain undeveloped theoretically and therefore fail to provide fully the kinds of understanding and explanation that scientific scholarship aims to provide. For example, although behaviororiented approaches have proven useful for generating descriptions of types and sequences of interactions that can distinguish distressed from nondistressed couples, such approaches seem to be less effective for generating explanations of why these differing interactions occur. We suspect that in order to explain marital processes and outcomes more fully, and not just describe them, scholars will need not only to expand their models but also to deepen them.

\section{The Need to Consider Alternative Views of Theory and Scientific Inquiry}

We find the vast majority of contemporary calls for explicit theory development and more careful theorizing of marital relations to be calls simply for "more gas" rather than a "shift in gears." Indeed, much of value can be done within the existing paradigm or received view. For example, Bradbury, Cohan, and Karney (1998) suggest that a social learning/ behavioral perspective has served as a foundation for much of psychological research on conceptualizing marital change. They acknowledge the value of this theoretical perspective, but they also assert that it has limitations. They suggest an "alternative view" that incorporates stressful events and individual differences into the behavioral model of marital change. Their alternative is an important contribution to our theoretical understanding of marriage, but it also represents "pressing on the gas" in that it remains within the received view of scientific inquiry.
Such emergent frameworks offer great promise as heuristics for organizing existing findings and identifying new lines of inquiry, but the majority continue to be based in a behavioral account of marriage. Although this allows these models to build on the strengths of existing behavior-oriented research, too much emphasis on observable interaction patterns may continue to constrain theory development.

Much marital scholarship of value has been done and is yet to be done within the paradigmatic boundaries of the received view, but we can do much more. Indeed, the welldocumented limitations of positivism and the received view of science (e.g., Slife \& Williams, 1995) suggest that a thorough understanding of marriage cannot come only from within the mainstream perspective. Although increasing our speed from 5 miles per hour to 10 miles per hour in first gear is laudable and even important, we need to change gears, to make a "second-order change" (Watzlawick et al., 1974), if we are to come to a fuller theoretical understanding of marriage.

\section{ALTERNATIVE PRACTICES FOR IMPROVING THEORIZING ABOUT MARRIAGE}

Despite the fact that marriage scholarship within the received view has hegemony within the academic community (in tenure decisions, for example), within grant-giving institutions, and even within popular culture, there is a long tradition of approaching marriage from different paradigmatic frames (Guba \& Lincoln, 1994). In what follows, we suggest that the time is ripe for marital scholars to shift gears and engage in sustained, rigorous theoretical analysis of marital research and scholarship. We attempt to articulate both the process and the value of the kind of theorizing we envision by providing three brief illustrations of the kinds of theoretical practices we view as necessary to advance the field: (a) analysis of basic ontological assumptions grounding marital knowledge claims, (b) analysis of basic epistemological assumptions informing 
marital research, and (c) analysis of evaluative dimensions of marital scholarship (i.e., what constitutes the "good marriage"). Due to space limitations, we cannot present our argument to the degree or with the depth that we would have preferred. Indeed, our three illustrations must be read as suggestive rather than definitive. Nor should these illustrations be taken as exhaustive of the potential payoff we anticipate from this kind of work. Instead, taken together, they represent our argument for rigorous theoretical examination of grounding assumptions, the kind of theoretical analysis that can offer the field a new "gear" through which to understand marriage.

\section{Examining Ontological Assumptions in Marital Scholarship}

All forms of marital scholarship make ontological assumptions that ground their knowledge claims about marriage. Such foundational assumptions about marriage have far-reaching implications for scientific work and intervention on family life. Careful examination of ontological assumptions can form a "first step toward generating better work" as we "delve deeply into the theories and findings" of contemporary scholarship on marriage (Bradbury et al., 2000, p. 975).

Although current marital scholarship makes a number of important grounding assumptions, here we examine ontological assumptions dealing with how marital scholarship understands the human actor. All forms of marital scholarship make assumptions about what it means to be a human being. In some theoretical frameworks, such as exchange and rational choice theories, these assumptions are clearly formulated and discussed, whereas in others they often remain hidden and unexamined, as in most behavioral models of marital interaction. Nevertheless, how marital scholarship understands the human actor has major consequences for how we understand the marital relationship and what kinds of interventions we might recommend. To illustrate the value of the practice of questioning ontological foundations, we focus our analysis on the grounding assumptions of social exchange and rational choice (SE/RC) theories.

\title{
- SPOTLIGHT ON THEORY
}

\section{THEORY-DRIVEN COUPLE EVALUATION}

\author{
Luciano L'Abate, Georgia State University
}

theory of personality socialization is evaluated through models in the laboratory;
through the use of self-report, paper-and-pencil tests; and in primary, secondary,
and tertiary prevention. It consists of three metatheoretical assumptions: (a) an assump-
tion of horizontality, or width of relationships, consisting of emotionality, rationality,
activity, awareness, and context, evaluated with the Relational Answers Questionnaire
(L'Abate, 2003, in press; L'Abate \& De Giacomo, 2003); (b) an assumption of verticality,
or depth of relationships, described according to the four levels of presentation/public,

(continued) 


\section{- SPOTLIGHT ON THEORY continued}

phenotypic/private, genotypic/internal, and historical/developmental, evaluated qualitatively through interviews; and (c) an assumption of settings, such as home, school/work, surplus leisure time, and transit, evaluated objectively through time analyses and subjectively with the semantic differential.

Two requirements are (a) expansion of monadic constructs to intimate relationships and (b) verifiability and accountability for theoretical models. Two major assumptions deal with abilities to love and to negotiate, their combination, and their contents, evaluated with (a) "What Applies to Me That I Agree With?" (WAMTIAW?; L'Abate \& De Giacomo, 2003), (b) a negotiation potential enrichment program, (c) a negotiation workbook (L'Abate, 1986), and (d) face-to-face interviews and prescribed tasks in psychotherapy. The contents of what is exchanged between partners are condensed into the Triangle of Living-composed of Being/Presence, Doing/ Performance, and Having/Production—and evaluated through a planned parenting workbook.

Personal and couple identity differentiates developmentally through the Likeness Continuum according to a dialectical curvilinear model composed of symbiosis, sameness, similarity, differentness, oppositeness, and alienation, evaluated with the Likeness Scale, the Likeness Grid, and WAMTIAW? In primary prevention, this model is evaluated with an enrichment program; in secondary prevention, it is evaluated with the "Who Am I?" workbook.

From the Likeness Continuum, three styles in relationships are derived: (a) most dysfunctional, Abusive-Apathetic; (b) semifunctional, Reactive-Repetitive; and (c) most functional, Creative-Conductive. These are evaluated with (a) the Problems in Relationships Scale (PIRS), (b) a negotiation potential enrichment program, (c) assignments in a negotiation workbook, and (d) face-to-face interviews in psychotherapy.

The PIRS, with 240 items, measures 20 potentially conflictual couple dimensions matching 20 written homework assignments. Individual partner scores have no meaning except in comparison with scores from the other partner. A discrepancy score between partners correlates significantly and negatively with Spanier's DAS. The PIRS is scored also for the three styles mentioned above.

Importance, as shown by care and concern for self and intimate others, as ascribed and attributed to self and intimates, produces four propensities: (a) Selfulness, positive attribution of importance to self and intimate others; (b) Selfishness, positive attribution of importance to self and negative attribution to others; (c) Selflessness, positive attribution of importance to others and negative attribution to self; and (d) No-Self, negative attribution of importance to both self and others. This model has been evaluated extensively with (a) the Self-Other Profile Chart, showing clear relationships with the attachment model (L'Abate, 2003; L'Abate \& De Giacomo, 2003); (b) the Dyadic Relations Test (Cusinato \& L'Abate, 2003); and (c) a workbook developed from that test.

Priorities, or what is important to self in relationship to intimates, have been evaluated with (a) the Priorities Grid and the Priorities Inventory, (b) a helpfulness enrichment program, and (c) an assignment in a negotiation workbook (L'Abate, 1986).

(continued) 


\section{SPOTLIGHT ON THEORY continued}

Intimacy in couples has been evaluated with (a) the Sharing of Hurts Scale, (b) an intimacy enrichment program, (c) an intimacy workbook, and (d) the Sharing of Hurts therapeutic task for couples (L'Abate, 1986; L'Abate \& De Giacomo, 2003).

Three additional models derived from the assumptions and models of the theorythe Drama Triangle (victim, persecutor, savior), distance regulation (pursuer, distancer, regulator), and the process of negotiation-are evaluated with matching assignments in (a) a depression workbook for couples (L'Abate, 1986) and (b) a negotiation workbook (L'Abate, 1986). One can evaluate the whole theory using a parenting workbook for couples (L'Abate, in press).

Although social exchange theories and rational choice theories have different historical roots (i.e., behaviorism and classical economics, respectively; Rigney, 2001, pp. 101-120), they share a common commitment to understanding social life as reducible to the actions of individuals. This commitment, commonly called methodological individualism, assumes that social entities such as marriage can be accounted for primarily or ultimately in terms of individual actions (see Udehn, 2002). For example, George Homans (1970), the main author of social exchange theory, argues that "all social phenomena can be analyzed without residue into the actions of individuals" (p. 325). Other approaches to marriage research also adopt methodological individualism as the mode of explanation, but SE/RC theories incorporate what might be called "ontological atomism," or the view that "basic human needs, capacities, and motivations arise in each individual without regard to any specific feature of social groups or social interactions" (Fay, 1996, p. 31). SE/RC theories start with the assumption that individuals are "the bearers of sets of given, discrete, nonambiguous, and transitive preferences" (Hechter, 1987, p. 30). Individual preferences or needs are independent of social groups, cultures, or social institutions and are located in and derived from the individual.

Beginning with the view that individuals have sets of needs, wants, and preferences, $\mathrm{SE} / \mathrm{RC}$ theories account for individual action in terms of how well such action fulfills the needs and preferences of the individual; in other words, human beings are fundamentally self-interested. Individual actions are therefore understood as the results of actors' evaluating possible courses of action in terms of how well they will maximize rewards over costs. Therefore, "every individual voluntarily enters and stays in any relationship only as long as it is adequately satisfactory in terms of his rewards and costs" (Thibaut \& Kelley, 1959, p. 37). This approach to understanding marriage assists family scholars in giving accounts of variations in marital stability and marital satisfaction at specific points in time, two common foci of marital research. Yet, if we maintain a commitment to the grounding assumptions of SE/RC theories, the approach struggles to account for change over time in marital satisfactions. Because SE/RC theories reduce social relations to self-interest, they must account for relationship change as either change in the values, wants, or preferences of the individual actor or change in the objective conditions for maximizing some set of stable preferences.

SE/RC approaches have difficulty accounting for how and why marital relationships develop because they lack a fully adequate conception of the human actor. Our argument builds on, but is more than, several common criticisms leveled against SE/RC approaches: (a) that actors don't really engage in rational calculation of costs and rewards in 
the ways presupposed by the theories (Root, 1993, pp. 100-123), (b) that actors lack sufficient information to make rational choices about alternative courses of action (Procter, 2000), (c) that emotional aspects are more important than SE/RC theorists grant (Peggs \& Lampard, 2000), (d) that actors cannot be understood as acontextual or atomistic selves (Regan, 1993), and (e) that actors cannot be reduced to acting out of self-interest without the loss of valuable human motivations, such as morality and altruism (Procter, 2000; Rigney, 2001; Root, 1993, pp. 173-204). We agree with many of these criticisms, but we also assert that SE/RC approaches are of limited utility for increasing our understanding of marital development because they assume features of the self that need to be brought into theoretical and empirical relief. Rather than assuming that the self is composed of a set of values, needs, and preferences and is driven to realize them, marital scholars need to ask why actors have the values and preferences they do at varying points in the course of marriage. In this way, we not only subject our conceptualization of the human actor to theoretical critique, but we also open the door to a fuller empirical analysis of marital change and development. This is the case because the values, needs, and preferences through which spouses determine the attractions and barriers associated with their relationship become areas in need of explanation rather than mere assumption or description. Additionally, rather than assuming that actors act in the name of self-interest, marital scholars can seek to ascertain when, where, and why selfinterest might be an overriding concern and when, where, and why other forms of action inform the marital relationship.

\section{Examining Epistemological Assumptions in Marital Scholarship}

In this subsection, we examine contemporary behavioral approaches in an attempt to illustrate why rigorous analysis of epistemological assumptions is crucial to theorizing about marriage. To illustrate why a commitment to epistemological assumptions contributes to the formation of particular knowledge claims about marriage, we contrast the behavioral approach with contemporary feminist, philosophical, and religious approaches to marriage.

Behavioral epistemology. In the past two decades, psychologists have advanced knowledge claims of marital relations by challenging the SE/RC perspective and research findings acquired primarily through survey methods. These challenges have largely centered on the assertion that studying what people say about themselves is not a substitute for studying what they do. The SE/RC approach has been faulted as "a theory in how people perceive interaction, not a theory of interaction per se" (Gottman, 1982, p. 950). Instead, psychological researchers propose to study marital interaction as an "exchange of behaviors" (Bradbury et al., 2000, p. 965) and suggest observational and daily diary techniques as the methods of choice (for a review, see Gottman \& Notarius, 2000). The aim is not simply to catalog various behaviors prevalent or absent in marital relations but to discover the behavioral sequences productive of (dis)satisfaction in marriages.

The emphasis on behavior has resulted in some important methodological developments in the study of marriage. Although behavioral researchers maintain an allegiance to marital quality as the dependent variable, how they measure marital quality has changed, shifting from a focus on both frequency of certain types of behaviors and evaluations of the marriage to a focus almost exclusively on level of satisfaction. This enables researchers to posit behavioral patterns as predictive of (dis)satisfaction in marital relations rather than confounded with it (Fincham \& Bradbury, 1987) and thus to produce evidence for "the guiding premise of the behavioral approach to marital quality," which is "that positive and constructive behaviors enhance marital quality and negative or destructive behaviors are harmful" (Kluwer, 2000, p. 68).

Scholars who take the behavioral approach often pride themselves on being 
more "scientific" in their work than those who use other approaches to understanding married life and tend to regard other theoretical perspectives on marriage as imaginations "not based on empirical knowledge" (Gottman, 1999 , p. 6). Instead, behavioral researchers propose to develop "a real theory of how marriages work and fail to work" through empirical analysis of "what real couples do to accomplish the everyday 'tasks' of being married" (Gottman, 1999, p. 7). However, behavioral theorists adopt an insufficiently critical epistemological framework for the study of married life. Their claims rely on a theory/data split that assumes that a simple recording of observable events produces atheoretical evidence. Such claims are not without their critics and amount to the adoption and championing of one of a number of possible epistemological frameworks for the scientific study of marriage.

By understanding the epistemological commitments of behavioral researchers, we can help to make sense of why they rarely discuss their ontological assumptions explicitly: They seek to present themselves as merely reporting observations and discovering simple behavioral patterns. Nevertheless, the behavioral approach does entail critical ontological assumptions regarding the human actor and what it means to be married.

Alternative epistemologies. When seen from within the received view of scientific inquiry, behavioral epistemology makes sense. However, when it is viewed from alternative epistemological standpoints, certain blind spots start to emerge. In particular, atheoretical observation is revealed to be less benign than it may at first appear. One can see this point most clearly when one adopts the epistemological standpoint offered by critical theory (a blanket term often used to describe several alternative paradigms, including neo-Marxism, feminism, materialism, participatory inquiry, poststructuralism, and postmodernism; for reviews, see Guba \& Lincoln, 1994; Lincoln \& Guba, 2000). Guba and Lincoln (1994) suggest that the "common breakaway assumption" of critical theory from the received view is an epistemological difference, a difference suggesting that epistemological assumptions are formative claims of knowledge about families. We illustrate this difference through a discussion of feminist and recent religiocultural theorizing on marriage.

Of all the forms of critical theory, feminist theorizing has probably had the largest impact on the field of marriage studies. As Fox and Murry (2000) note, "Across varied disciplinary fields, feminism as an intellectual orientation has taken a critical eye to received traditions of scholarship and epistemology." Thus this perspective provides marriage scholars with new and different concepts, questions, methodologies, and ways of organizing and seeing research and research findings (Thompson, 1993).

A variety of different and even competing views exist within feminist theory, but most scholars suggest that all strands of feminist theory share certain themes or assumptions (Fox \& Murry, 2000; White \& Klein, 2002), including the following: (a) Women's experiences are central, normal, and as important as men's experiences (Wood, 1995); (b) gender is a basic organizing concept in social life (Thompson, 1993; Wood, 1995); (c) a feminist gender perspective presupposes that gender relations are shaped by historical and cultural contexts and must be studied in those contexts (Lincoln \& Guba, 2000); and (d) feminist theory is emancipatory (White \& Klein, 2002). These assumptions have allowed feminist-informed scholars to observe and conceptualize aspects of marriage that were previously hidden from view. For example, many feminists see traditional marriage as problematic for women. They assert that traditional gender-structured marriage, with its centrality in patriarchy, devaluation of women's contributions, and hierarchy of gender, is oppressive and costly to women in financial, emotional, and physical terms (Blaisure \& Allen, 1995).

As noted above, a behavioral epistemology leads us to explain marriage as primarily a matter of explaining each individual's marital satisfaction. A feminist epistemology, on the other hand, enables researchers to ask why 
women would be "satisfied" with, and not see as unfair, the often imbalanced division of work in the marital relationship (Blaisure \& Allen, 1995; Thompson, 1993). Theorizing marriage is no longer reducible to seemingly atheoretical observations of individual spouses' satisfaction. Feminist inquiry calls for critical examination of the ideology and practice of marital relations (Blaisure \& Allen, 1995).

A similar critique of behavioral epistemology can be informed by religious and philosophical understandings of marriage. As with feminist and other critical theories, a central aspect of this religiocultural view is that our observations of marriage are informed by our theoretical commitments. In this case, our theoretical commitments can be informed by religious traditions and concepts. This type of mixed discourse is possible because of an often overlooked symmetry between religious thought and secular thought. All types of thinking, whether religious, philosophical, or scientific, involve a complex interweaving of several dimensions of thought. These include foundational metaphors that convey fundamental assumptions about views of reality, human nature, and other aspects of the human condition. A careful analysis of all types of thinking invariably reveals assumptions and judgments at the ontological, epistemological, and teleological levels. As Browning (2003) notes, religiously informed scholars hold that "the deep metaphors of all practical thinking have the status of faith-like assumptions" (p. 3). Therefore, because such metaphors "can be uncovered in all instances of practical thinking, the distinction between explicitly religious practical thinking and so-called secular thinking is not categorical" (p. 3). Both scientific and religious forms of reasoning are based on assumed metaphors about the basic nature and structures of life; therefore, religiously based concepts and perspectives can make valid contributions to family theory development. Of course, for religiously informed theories to influence social scientists, they must be put forward in ways that allow scholars to use scientific methods to establish the credibility of their ideas. This can happen when scholars form mixed discourses in which religiously based concepts are interwoven with theoretical arguments that can be expressed in recognizable forms of scientific theory and philosophy.

An example of this type of theory development in the marriage field is the work of Browning and his colleagues, who have explored the possible relevance of Western religious traditions to contemporary family issues, including marriage (Browning, 2003; Browning, Conture, Franklin, Lyon, \& MillerMcLemore, 1997). They use the term critical familism to identify a paradigmatic position that abiding themes from religious traditions can be coupled with the best insights of contemporary human sciences to offer a unique understanding of marriage. Critical familism is "critical" in that it "attempts to expose, critique, and reform distortions of social, economic, and political power which function to block or undermine free formation and support of the equal-regard mother-father partnership" (Browning, 2003, p. 4). According to this alternative perspective, the principles supporting such critique can be found within Jewish, Christian, and other faith traditions and gleaned from insights drawn from contemporary moral philosophy. These traditions recognize marriage as a central aspect of both personal and collective religiocultural aspirations and highlight the need for scholars to consider the "mutual regard" (e.g., equality, commitment, self-sacrifice, other-centeredness) and social institution (e.g., community support, social goods) dimensions of the marriage relationship.

\section{Examining the Question of the Good Marriage}

What is a good marriage? This deceptively simple question plays a central role in how researchers study marriage and, in turn, how marital therapists and educators focus their intervention efforts.

The received view of the good marriage. Scholars working within the received view have defined the good marriage predominantly 
in terms of spousal satisfaction and relationship stability. In their review of longitudinal research on marriage, Karney and Bradbury (1995) point out that "marital researchers have rarely explored outcomes other than satisfaction or stability" (p. 16). Indeed, although there has been a recent shift in focus in marriage scholarship (i.e., from status variables to interaction processes), the way current scholars define the "good marriage" has changed little since the early theorizing of the 1940s and 1950s. The conceptualization of marital quality according to the two primary factors of marital stability and marital satisfaction has been one of the most enduring aspects of marital scholarship through the 20th century.

Although marital satisfaction has shown remarkable endurance as the primary criterion used to define the good marriage in the social sciences, it would be inaccurate to say that this construct has not changed or progressed over time. Furthermore, scholars operating within the received view have begun to recognize that we have been overly dependent on the behavioral and social exchange views of "marital satisfaction" as the outcome variable of choice (e.g., Fincham, Beach, \& Kemp-Fincham, 1997). During the past decade, scholars have questioned some of the conceptual assumptions that have provided the foundation for how marital satisfaction has traditionally been defined and measured (for a review, see Bradbury et al., 2000). For example, Fincham et al. (1997) have challenged the long-standing assumption that researchers can measure marital satisfaction accurately by using bipolar or singledimension measures (e.g., dissatisfied versus satisfied). An emerging line of research supports this challenge and suggests that positive and negative evaluations in marriage can be conceptualized and measured as separate, although related, dimensions (see Fincham \& Linfield, 1997). Reconceptualizing marital satisfaction in this way has potentially farreaching implications and will enable more detailed descriptions of change in marital satisfaction over time and the factors that account for these changes.
Theorizing the good marriage. Although recent reconceptualizations of marital satisfaction have invited scholars to view the construct in broader and more nuanced ways, these developments have tended to represent refinements of the existing definition of a good marriage rather than an alternative definition. Recently, however, some scholars have begun to question the assumption that satisfaction and stability should be the primary outcomes in marital research and practice. In particular, they have questioned the assumption that personal satisfaction or happiness is the defining feature of a good marriage (Fowers, 2000). An alternative to this "communication-based satisfaction" definition of marital quality is available in concepts that relate to personal characteristics and focus on what spouses contribute to marriage, such as generosity, loyalty, sacrifice, friendship, devotion, maturity, and goodwill (Fowers, 2000; Gottman, 1999; Stanley, 1998).

Similarly, conceptualizations of the marriage relationship that transcend individual experience and emphasize companionship also provide alternatives to traditional definitions of the good marriage. Fowers (2000) has argued that concepts such as partnership, teamwork, cooperation, collaboration, and coordination represent a view of the good marriage that is couple centered rather than individual centered. Whether or not one agrees with Fowers regarding what constitutes the good marriage is not important; the point we wish to emphasize is that his alternative conceptionalizations are healthy for the field, enabling us to see dimensions of marriage that may have gone unnoticed in the received view. The integration and innovation that Fowers has produced are direct results of the kind of sustained, explicit, and rigorous theoretical analysis we are advocating for the field of marriage scholarship.

We also see the benefits of shifting gears and theorizing the good marriage in another line of critique of marital satisfaction. Loveless (2000) argues that traditional notions of marital satisfaction assume that all happiness is functionally equivalent, when in fact differences in marital satisfaction between spouses 
and couples may differ not only in degree, but also in kind. Specifically, he asserts that "all happiness reported by those studied is assumed to be equivalent in kind and varying only in quantity, where in fact it may have distinct types or subtypes with significant qualitative differences" (p. 7). If all reported satisfaction in relationships is treated as equivalent, there is no way to distinguish, for example, between a spouse who is happy because he gets to buy everything he wants and one who is happy because he has a deeply committed friendship with his partner. Drawing from moral philosophy, Loveless identifies three types of happiness that spouses and couples might find in marriage: hedonism (the relatively indiscriminate satisfaction of desires), individualism (in which one discriminates between worthwhile desires and harmful ones, and then chooses to satisfy the former), and altruism (in which the needs of others, not personal desire, are one's primary concern, and happiness occurs as a by-product of serving others in a perceived human unity). This opening up of the concept of marital satisfaction through rigorous theoretical examination of grounding assumptions enables marital scholars to produce new typologies that may connect well with existing research on attributions in marriage and help explain varying levels of resilience of satisfaction over time in marriage, in that some types of satisfaction may be more stable than others.

\section{- SPOTLIGHT ON METHODS}

\section{STUDYING MARRIAGES LONGITUDINALLY}

Frank D. Fincham, University at Buffalo

Thomas N. Bradbury, University of California, Los Angeles

W ith the recent transition among marriage scholars to the study of the development of marital dysfunction, it seems that the prospects for understanding the determinants of marital well-being have never been brighter. Carroll, Knapp, and Holman's analysis of the rudimentary state of theories of marital development, however, provides a welcome counterpoint to this view. Why? Absent identification and clear specification of core constructs and recognition of the limits of longitudinal research for studying causal processes, the value of longitudinal research is moot.

\section{CORE CONSTRUCTS IN LONGITUDINAL RESEARCH}

\section{Slaying the Bipolar Bear}

Marital scholars typically conceptualize and assess core constructs using bipolar evaluative continua. Such bipolar assessments function like the balance knob on a stereo,

(continued) 


\section{SPOTLIGHT ON METHODS continued}

which does not allow left (positive evaluations) and right (negative evaluations) speakers to function independently. They therefore necessarily provide a limited picture of change. In studying the development of marital dysfunction, it is theoretically important to know whether happily married spouses who have become distressed spouses first increased in negativity before decreasing in positivity, as opposed to a progression in which negativity increased at the same time positivity decreased. Such a progression may, in turn, differ in important ways from one in which a steady decline in positivity results in marital distress. Documenting the existence of different avenues of change in marital constructs, examining their causes, and exploring their consequences is a program of research that could do much to advance understanding of how marriages succeed/fail. Moving beyond bipolar conceptualizations has the added advantage of drawing researchers' attention to new phenomena, such as ambivalence in marital and family relationships.

\section{Continuity or Discontinuity?}

Many researchers assume that marital well-being is a continuous variable, whereas clinicians using a threshold score to define "recovery" following marital therapy imply the existence of a discrete taxon. The continuity/discontinuity of core constructs is critical for longitudinal research because it has implications for the plausibility of linear models versus nonlinear models. Nonlinear models often imply discontinuities, and so a continuous distribution of scores might be taken as a strike against theories based on such models. Likewise, the recent discovery of taxonicity in marital well-being challenges longitudinal findings that have thus far assumed continuity in variables.

\section{LONGITUDINAL RESEARCH AND CAUSALITY}

\section{Causal Discovery Versus Causal Inference}

Researchers tend to overestimate the value of longitudinal research for illuminating the causes of marital dysfunction. Longitudinal studies of marriage (without randomized experimentation) are not useful for discovering causal relations and, when sample selection bias due to separation/divorce is handled improperly, can even create the appearance of (spurious) effects over time. Such longitudinal data are always subject to more than one interpretation. At best, we find ourselves making causal inferences with greater or lesser confidence. To tip the balance toward greater confidence, we must work as hard at eliminating plausible explanations as we do at working to identify statistically reliable effects.

\section{Testing the Null Model Versus Testing Competing Models}

Another way to increase our confidence in our ability to draw causal inferences is to move beyond testing data against the null model. Although it is not trivial to show that a model fits the data, an unknown number of additional models may also fit the data. Comparing the somewhat inconsistent findings of longitudinal research on marital

(continued) 


\section{- SPOTLIGHT ON METHODS continued}

conflict and marital well-being (which tests against the null model) with the fairly consistent findings in comparative treatment outcome research (which tests different theoretical positions) illustrates this point well. Although we can never overcome the third variable problem in longitudinal research, we can and should do more to address this problem by examining competing models. This points to the strong need for a clear theoretical or empirical foundation that outlines expected causal relations among constructs, a characteristic that is all too often absent in longitudinal studies of marriage.

\section{CONCLUSION}

Research on marriage has evolved from a reliance on cross-sectional studies to the use of two-wave longitudinal designs, to the recognition that multiwave longitudinal studies may provide the greatest vantage point from which to understand how marriages develop and change. We need refined theoretical frameworks to guide and integrate the data collected in studies using these designs, and Carroll et al. provide welcome grist for this mill. In the same way that a sophisticated theory gains us little when it is combined with a weak research design, a strong design will underperform when its underlying theoretical postulates are vague or poorly conceived.

The benefits of applying theoretical analysis to assumptions that are often taken for granted in marital scholarship are also exemplified in recent work on the place of communication skills in the good marriage. In accordance with current definitions of the good marriage that hold that marital satisfaction and stability are largely determined by how well couples handle conflict and exchange positive interactions with each other, many couple-based interventions emphasize increasing relationship satisfaction by improving communication skills. However, Burleson and Denton (1997) note that "a careful review of the relevant literature reveals that the impact of communication skills on marital satisfaction has been assumed much more frequently than it has been shown" (p. 886). Their review confirmed their suspicion that the "communication skills-deficit" model of marital competence has been largely assumed. Specifically, they found that spouses' communication skill levels did not differ as a function of marital distress. Distressed husbands and wives were no less skilled in communication than their nondistressed counterparts-a result that contrasts directly with the frequent claim that distressed couples suffer from deficits in communication skills. Although Burleson and Denton found that distressed couples did not have poorer communication skills than nondistressed couples, distressed couples did express significantly more negative intentions toward each other than did nondistressed couples. These findings support the argument that there are many theoretical reasons for poor communication behavior. Or, put differently, approaches that highlight communication behavior can take us only so far, because they have not adequately theorized marriage. Marital scholars need to shift gears by calling grounding assumptions into question and engaging in theoretical practices that can lead to real progress in our understanding of the dynamics of marital relations.

Improving our understanding of the interpersonal aspects of marriage is not enough, however, and may limit the kinds of theoretical examinations that are brought to bear on 
marriage. This can be seen in the work of a handful of scholars who have recently called for a more systematic inclusion of the social domain in definitions of marital quality (Browning, 2003; Doherty \& Carroll, 2002). In essence, these scholars caution marital researchers and practitioners about contributing to the deinstitutionalization of marriage and call for a deeper theoretical analysis of the good marriage that recognizes marriage as a social institution that involves important social, intergenerational, and public dimensions. From this perspective, our call for more rigorous theorizing about marriage is not just an academic issue; such theorizing is critical for the well-being of real families, communities, and societies.

When viewed through a moral-social lens, marital health can be expanded beyond traditional approaches that focus almost exclusively on spouses' happiness with the relationship and the permanence of the union. While recognizing the importance of spousal well-being and evaluations of the relationship, socially informed perspectives also stress that marriage is part of a familial and social ecosystem and, therefore, has a number of interdependent stakeholders with interests in the quality of the marriage relationship. The unavoidable connection of marriage to these stakeholders defines much of the social dimension of marriage. Taking this type of perspective, Doherty and Carroll (2002) have developed an ecological model of marital quality that conceptualizes marital health, or well-being, at four ecological levels: the individual, the family, the community, and the society. Within this model, the good marriage is defined as an ongoing process of balancing the mutually interdependent needs of the stakeholders in the marital ecosystem. This type of perspective stands in stark contrast to many of the current conceptualizations in the couples and marital domain that implicitly encourage individuals to operate primarily from self-interest and from concern with maximizing their personal fulfillment and happiness. Instead, socially informed approaches to marital well-being stress the recognition of shared morality that emerges from marital partners' position as relational beings in a social world.
None of the scholars whose work we have reviewed in this section seek to impose value-laden definitions of the good marriage dogmatically on marital scholars, families, or societies. Nor do they fall back on a version of the atheoretical myth and/or a moral relativism, which insists that only individuals can define for themselves what constitutes the good marriage. Instead, they make explicit arguments for their positions and, in so doing, offer us examples of the kinds of theoretical analysis the field of marital scholarship needs to encourage. Whether or not we agree with any or all of these scholars is not the pointthe point is that by making arguments that are explicit rather than hidden, sustained rather than fleeting, rigorous rather than indulgent, examined rather than assumed, marital scholars will be able to produce better work and increase our understanding of marriage.

\section{CONCLUSION}

Marital scholarship today stands at a crossroads. Like many of our colleagues, we are optimistic for the field given that marriage is currently drawing widespread attention from scholars of diverse disciplinary backgrounds and that the previous generation of marriage scholarship has generated a rich foundation from which to build. However, we also share the doubts expressed by some marital scholars that the descriptive-empirical approaches that have guided marital research for the past 30 years will be sufficient to guide the next generation of research. We believe that the impact of future marriage scholarship-both in research and in application-will depend on an infusion of theoretical-explanatory approaches that can unify and synthesize existing research and guide future studies. We also believe that the field cannot be intellectually honest or professionally responsible unless marital scholars openly grapple with the social and moral meanings of marriage as well as the developmental aspects and contexts that inform such meanings. However, all of that said, our optimism outweighs our pessimism as we look to the future of theorizing about marriage. 


\title{
CASE STUDY
}

\section{CULTURAL NARRATIVES AND INDIVIDUAL EXPERIENCES IN RELATIONSHIPS}

\author{
Richard Bulcroft, Western Washington University \\ Linda Smeins, Western Washington University \\ Kris Bulcroft, Western Washington University
}

$\mathbf{T}$ he research we discuss here began with a student's question. Soon to be married, she hoped to do a project on marriage rituals, including the honeymoon, but she found that very little research on the topic was available. How could this be? Clearly the honeymoon had been widely overlooked. What few academic references to honeymoons she found were focused on the functional value of honeymoons for society or the significance of the honeymoon as a critical role transition in the development of families (Bulcroft, Smeins, \& Bulcroft, 1999). These explanations seemed inadequate, however, as honeymoons appear to be becoming more important in spite of the declining significance of marriage and a reduced need for transitional adjustment due to increased levels of cohabitation.

To help fill the void, we initiated a project that began with a historical analysis of articles in the popular press and evolved to include a cultural analysis of honeymoon locations and a longitudinal survey of newlyweds. What started out as a question about honeymoons grew into a project with greater theoretical significance for understanding marriage and romantic relationships in latemodern society. It also developed into an exemplar of how two quantitative sociologists who are well indoctrinated into the scientific process and survey methods can work together with a qualitative art historian who is well versed in postmodernism and visual cultural analysis.

\section{PHASE I: THE HISTORICAL CONTEXT}

Adopting a social constructionist perspective (Bulcroft et al., 1999), we viewed the honeymoon as an event with potentially changing meaning linked to larger social processes and emergent cultural themes. This meant that our first task was to uncover these meanings at the cultural level. We began with a qualitative content analysis of articles about honeymoons published in the popular press since 1880. We then treated the contents of these articles as elements of a story or cultural "narrative" (Bulcroft et al., 1999) involving locations, sets of actors, role relationships, activities, themes, and plots. This approach grew out of the story structure of many of these articles and the adaptation of ideas from cultural studies of architecture and tourism (Bulcroft et al., 1999). We adopted the following assumptions about physical locations: that they provide opportunities for specific types of experiences, that they are imbued with symbolic meanings, and that they are mapped to culturally constructed stories. In particular, we found cultural studies of romanticism and the "myth of the exotic" (Bulcroft et al., 1999) to be useful in guiding our research. The emergence of romantic ideals linked to exotic locations has been attributed in these studies to a growing tension between rationality and emotions-a tension also noted in the postmodernist literature on identity and the sociological literature on modern relationships (Bulcroft et al., 1999). 


\section{CASE STUDY continued}

Although we found similar story elements across the years, we did discern four qualitatively distinct narratives. In the earliest time period examined (pre-1940), the honeymoon story was largely one of domestic role enactment that took place in mostly natural settings and in rudimentary accommodations that facilitated domestic role activities. Beginning around 1940, however, a different story line began to emerge. Still occurring in mostly natural settings, honeymoons began to take on greater interpersonal significance. Increasingly, articles highlighted the intimacy aspects of the experience and alluded to the potential for later marital disaster should the honeymoon not go well. Gone were domestic role activities, as honeymoon locations went from housekeeping cabins to full-service accommodations where the couple was free to explore psychological compatibility. The risks involved in the honeymoon were portrayed as significant, and, for the first time, social scientists and other experts weighed in on the experience. By the 1960s, these concerns had all but disappeared from the cultural narrative, replaced by an emphasis on sexual and emotional gratification in luxurious accommodations filled with symbols of love and romance. Articles published during this time increasingly focused on planning to assure a rewarding experience, with a key element being the selection of a site that provided an unlimited supply of activities and services. This "all-inclusive" honeymoon was also evident in advertising. Today, this evolution has progressed even further, as a more hegemonic picture of the honeymoon has emerged involving exotic locales that provide a context for a narrative involving themes of perfection, authenticity, emotional fulfillment, sensuality, affirmation, and class privilege.

\section{PHASE II: A CULTURAL ANALYSIS OF HONEYMOON SITES AND ADVERTISING}

With elements of the contemporary cultural narrative identified, we began to work toward situating couples in this context by asking how they experience the narrative. How is the honeymoon imagined and made personal, and how are these imaginings actualized? These questions led us to research methods applied in visual culture analysis (Bulcroft et al., 1999). They also led us to progress to the micro level of personal experience. We began with analyses of representations in advertisements, then explored symbolic connections with actual experiences posed for couples at specific locations. Using industry studies to determine the most popular honeymoon destinations, we analyzed advertisements to understand how various possibilities for actualizing the imagined honeymoon are presented and how physical tourist settings offer closer scripting of the honeymoon narrative. Tropical locations expand the imaginings of romance, and at each specific location, couples are prompted to assume scripted identities. Using spatial and visual culture analysis, we examined how specific sites script the honeymoon through the organization of architecture, symbolism, and activities. Further, they map the sequence and pace with which the spatial organization will be experienced. Thus the cultural narrative becomes incorporated as part of the couple's personal biography, with the setting providing the necessary meanings of authenticity, heightened emotionality, intimacy, and status.

\section{PHASE III: MOVING FROM MACRO TO MICRO AND FROM QUALITATIVE TO QUANTITATIVE}

Returning to the scientific paradigm and concluding our journey from the macro to the micro, the final step in our research involved testing specific hypotheses derived from our cultural observations. Our analyses to this point suggested an alternative to functionalism as well as to many of the emerging modernist perspectives on relationships. Not only was evidence of functionality missing from 


\section{CASE STUDY continued}

the modern honeymoon, but we found no evidence for the more authentic, less gendered experience that modernist theories would predict. The honeymoon had become more universal, less spontaneous, and more scripted, elaborate, and feminine as society had become more modern. These observations led us to the alternative perspective of "risk society" theory (Bulcroft et al., 1999). Accordingly, we interpreted these narrative changes as a cultural response to the increasing invasiveness of rationality into our most intimate relationships, a growing sense of risk as a result, and, paradoxically, a tendency in late modernity to manage risk through formal, if not substantive, rationality. The honeymoon had become a highly planned and elaborate ritual for managing individual and couple identities, assuring the couple of an authentic emotional experience without the risks of failure, validating each spouse's free choice of a partner, and providing a wellorchestrated reflected appraisal of the couple as successful.

To test this perspective at the level of lived realities, we undertook a study of newlyweds before and after their weddings and honeymoons. As expected, we found that expectations have become highly uniform and that they reflect the cultural narrative of the exotic. Although nearly all respondents expected to take honeymoons, few expressed any specific functional reasons for doing so. Most identified romance and passion as reasons and downplayed the importance of staging, recognition, and symbolism. Paradoxically, a vast majority expressed strong preferences for honeymoon resorts in exotic locales and were more disappointed if these expectations were not fulfilled, although most couples expressed satisfaction with the event regardless of their experiences. Finally, and most important from a risk society theoretical perspective, we found significant effects of perceived risks in marriage on the importance of honeymoons, thematic accommodations, recognition as newlyweds, symbols of romance, and planning. Those respondents who perceived greater risks in marriage also expected more in the way of interpersonal adjustment and fantasy fulfillment outcomes on their honeymoons.

\section{CONCLUSION: LESSONS ABOUT THEORY AND METHODS}

What have we learned and where do we go from here? First, we learned that we have much to gain by exploring seemingly trivial aspects of everyday life. Second, we have come to appreciate the postmodern perspective of reflexivity as was evident in the role played by "experts" and "scientific" theory-building activities (especially functionalism and family development theory) in shaping the honeymoon narrative of the 1940s and 1950s. Third, we found added value in interdisciplinary collaboration. The concept of cultural narratives guided our coding of articles from the popular press, and spatial and visual cultural analyses helped us to understand how cultural narratives frame experiences and build personal biographies. Fourth, we came to understand the difficulties inherent in attempts to move from the macro to the micro. The idea that cultures develop in response to relationship conditions in a society to alleviate concern about those conditions makes it difficult to measure such conditions through individual questionnaires. Finally, we found a body of literature that contains a wealth of ideas for future research into both relationships and the life course (see this volume's companion Web site at http://www.ncfr.org/sourcebook). What began as a simple inquiry into a seemingly mundane everyday event has developed into a program of research into relationship formation patterns and life-course transitions in modern society. 


\title{
CASE STUDY
}

\section{COUPLES UNDER STRESS: STUDYING CHANGE IN DYADIC CLOSENESS AND DISTANCE}

\author{
Yoav Lavee, University of Haifa
}

O ver the past two decades, there has been a growing interest among family researchers concerning the effects of stress on marital relationships. This research has been guided, implicitly or explicitly, by family stress theory (Boss, 2002; Hill, 1949; McCubbin \& Patterson, 1983), which posits that adaptation to a crisis in the family social system is dependent on the nature of the event and its hardships, the resources available to the family, and the perception of the situation.

As a focusing lens through which to study marriages under stress, family stress theory has a number of strengths: It is relatively simple, easy to operationalize and test, and is useful for explaining a wide range of situations affecting the family. It also offers a means of predicting when declines in marital satisfaction are likely to occur and is useful for explaining change in marital quality and stability over time (Karney \& Bradbury, 1995). Although a number of other theoretical models have been developed that focus on marital relationships under stress (e.g., Bodenmann, 1997; Karney \& Bradbury, 1995), family stress theory has continued to guide research on this topic.

Indeed, the majority of research has supported the assertion that stressful events have a deleterious effect on marital relationships. Scholars have found this to be the case with respect to a variety of sources of stress, both normative life transitions and nonnormative and catastrophic events. However, a number of studies have also shown that stressful experiences may actually strengthen marital relationships, resulting in increased cohesiveness and tighter couple bonds. Other studies have found even more complex patterns of change in marital relationships. For example, relationships may change in certain dimensions but not in others, or they may be negatively affected in some aspects and positively in others (Lavee \& Mey-Dan, 2003). Indeed, Burr and Klein (1994), who studied family functioning and marital satisfaction along various stages of the coping process, conclude that "considerably more variation is seen in the way family systems respond to stress than is generally recognized in the stress literature" (p. 123).

Given the emphasis of family stress theory on marital outcomes, the theory's shortcoming lies in the lack of attention paid to systemic processes and interpersonal interactions that may explain different patterns of change. Therefore, a different approach is needed if we are to gain a better understanding of what transpires within couples and how intimate partners interact under stress. Examinations of short-term outcomes and changes in couple relationships under stress may shed light on these patterns and enhance theory building. The two studies reported below utilized different methodologies to investigate interactional processes among couples under stress.

\section{STUDY I. CLOSENESS-DISTANCE IN THE DAILY LIVES OF COUPLES: A REPEATED TIME SAMPLING STUDY}

A limitation of many studies that have dealt with the impact of stress on marital 


\section{CASE STUDY continued}

relationships is that they have assessed the effects of a stressful event on the relationship after the event has occurred. Thus it is hard to assess change in a relationship associated with the event from the findings of such studies. One approach to achieving a better understanding of what transpires within couples in times of stress is to employ a short-term longitudinal design and a repeated time sampling method to examine the repeated sequences of the effects of stress on the couple relationships (Larson \& Almeida, 1999). Such a method has been used for estimating the effects of daily stresses and strains on changes in dyadic closeness (Lavee \& Gilat, 2000).

Daily reports were collected from a sample of 94 couples over a 7-day period. These reports included checklists of daily hassles, interpersonal conflicts, and positive and negative mood, and a measure of the sense of dyadic closeness. In addition, the couple's marital quality, as a relatively stable characteristic of the marital system, was measured before the couples began reporting on their daily experiences.

The data were analyzed using the hierarchical multivariate linear modeling approach (Raudenbush \& Bryk, 2002), which is an application of hierarchical models with repeated observations nested within persons or couples (for a description of the analytic strategy, see Larson \& Almeida, 1999).

Excluding the first day of reporting, analyses were based on 564 diary days. A change model was estimated, namely, the extent to which a change in dyadic closeness from the previous day, as reported by one spouse, is related to the level of stress reported by the other spouse. In addition, the moderating effect of marital quality was estimated to enable an examination of whether the association of daily stress and change in dyadic closeness is shaped by it.

The analysis showed that for both spouses, sense of closeness was negatively associated with the other spouse's stress: The more stress a person experienced in a certain day, the less closeness (or more distance) his or her spouse reported. This effect, however, was stronger for women than for men.

Marital quality had a significant main effect on the level of closeness: Couples who had high-quality relationships reported more closeness than did those in distressed marriages, regardless of the stress level. However, in both happy and distressed couples, more stressful days were associated with increased dyadic distance.

These findings may suggest that daily stress has a negative influence on relationships. However, greater distance may not necessarily be bad for a marriage. It might be that in some couples, one or both spouses use "relationshipfocused coping” (Coyne \& Smith, 1991), whereby when one spouse detects stress in the other, he or she avoids behaving in ways that might be burdensome and refrains from making demands on the stressed spouse's time and attention. This may depend on the partners' approach-avoidance strategies and the couple's pattern of distance regulation under stress (Kantor \& Lehr, 1975).

\section{STUDY II. MARITAL RELATIONSHIPS AMONG PARENTS OF CHILDREN WITH CANCER: A QUALITATIVE STUDY}

A child's life-threatening illness is often characterized not only by its traumatic impact on the parents, but also by ups and downs in the child's condition, which are accompanied by rising and falling stress levels in the family. In a qualitative study of parents whose children had been diagnosed with cancer, in-depth interviews were conducted with 21 couples. A theme that ran through the interviews was that affective communication, supportive behaviors, and emotional closeness changed in times of heightened stress (such as immediately following the diagnosis, during signs 


\section{CASE STUDY continued}

of relapse, and in times of physical deterioration) as well as in times of reduced stress (such as when the child's condition improved, when the child was released from the hospital, when medical treatment was terminated, or when lab tests showed promising results).

Two opposite patterns of relationship changes were observed in stressful times versus less stressful times: Distancing couples pulled away from each other when relapse occurred or the child's physical condition deteriorated. Under heightened stress, such couples exhibited escalating tension and a growing emotional and physical distance. However, some of these couples tended to draw closer together again when the child's health improved. In contrast, bonding couples felt closer to each other soon after diagnosis and whenever the child's medical condition deteriorated, demonstrating more intimate and supportive communication. Two other couple types did not experience significant changes in their relationships. Distant couples had little affective communication and mutual support before the child's illness and remained distant from each other in both "good" and difficult times, and fluctuating couples went through periods of closeness and distance that appeared to be unrelated to the child's condition.

The analyses further indicated that these patterns of dyadic closeness and distance were related to the parents' emotional and behavioral reactions in times of heightened stress, their level of comfort with and reactions to their spouse's behaviors, and their approach or avoidance strategies in support seeking and giving.

\section{CONCLUSIONS AND IMPLICATIONS FOR RESEARCH AND THEORY}

Although most research indicates that experiencing stress has a deleterious effect on marital quality, studies also show a more complex pattern of relationship change. As the two studies reported above demonstrate, time sampling methodologies may enhance our understanding of the repeated sequences of marital relationship change under stress, and qualitative research may shed light on other processes of dyadic interactions and relationship change.

Some important questions still await further research and theory building: What determines couples' interactions under stress? Under what circumstances do spouses get closer together or become more distant from each other? What accounts for "ups and downs" in a relationship at various points in the stress process? Do different sources of stress and/or stress levels elicit different behaviors and different patterns of couple interaction? Does culture shape the ways in which marital partners regulate distance in time of stress?

Research that focuses on the adaptive process and ways of interaction among couples under stress may enhance theory building and help to increase our understanding of the complex patterns of change in marital relationships. 


\title{
DISCUSSION AND EXTENSION
}

\section{THEORIZING THE PARTICULARS OF MARRIAGE}

\author{
Bert N. Adams, University of Wisconsin-Madison
}

n Chapter 11, Carroll, Knapp, and Holman say that marriage is important in the family field and that we need to theorize about it. "Theorizing (about marriage)," they state, "is crucial." Carroll et al. discuss the "received view" of sociological theorizing and "the good marriage." The former is scientific positivism; the latter is the satisfied and stable relationship.

The contributions that make up this Sourcebook (and Bengtson et al.'s introductory chapter in particular) attempt to make it clear that positivism in its original form should no longer be considered the "received view." Theorizing includes the standpoints of both qualitative research and feminism, and is much broader than positivism. Even when Carroll et al. discuss the limitations of this supposedly "received view," it is not obvious from their comments that these limitations should be blamed on positivism. The limitations, which include "lack of theorizing about data," "an atheoretical myth," and "empiricaldescriptive work," are all related to the fact that findings are often reported without leading to an "improved theoretical understanding." This, however, is not necessarily the result of a positivist philosophy. In fact, case studies, subjective insights, historical studies, and so on may also be left at the descriptive level.

As for the satisfactory and stable marital relationship, there is much to discuss regarding whether this is the current expectation. Carroll et al. suggest that successful lifelong marriage is a highly valued goal for most people. However, recent writings and theorizing on marriage in Western capitalist societies show that economic individualism has made it possible for individuals and couples to desire/pursue the happy marriage rather than the stable marriage.

Carroll et al. make it clear that they see a particular type of satisfactory, stable relationship as the marital goal. They distinguish distressed couples from nondistressed couples, with the former characterized by negative interactions and negative or poor communication. In fact, their discussion of communication skills shows that their primary focus is the interactional, middle-class marriage, not the parallel lower-class marriage. In the latter, the purposes of marriage are sex and child rearing, not communication and friendship (Kerckhoff, 1974).

Likewise, the discussion of marital communication in general in terms of problem solving and the handling of conflict ignores Cuber and Harroff's (1965) finding that an "adjusted" marriage may, in fact, be conflict habituated. In other words, adjusted marriages may be either weak or conflictual in their communication patterns. Increasing our understanding of such marriages will require a much broader approach to theorizing than Carroll et al. take in Chapter 11.

Over and over, Carroll et al. make it clear that we need to theorize about marriage. Near the end of the chapter they state that "marital scholars need to 'shift gears' by calling grounding assumptions into question and engaging in theoretical practices that can lead to real progress in our understanding of the dynamics of marital relations." I doubt that anyone would disagree with this broad statement. However, aside from communication skills and a mention of systems theory, they 


\section{DISCUSSION AND EXTENSION continued}

do not make it clear what we need to theorize about regarding marriage. Thus, in the remainder of this commentary, I introduce some marital issues that need further theoretical consideration.

What is marriage? The issues of the definition and universality of marriage go back to Kathleen Gough's (1959) discussion of the Nayar. Cross-culturally, the issue of customary versus legal or government-sanctioned marriage has long been of interest. To this has been added the current topic of same-sex marriage. Then we have the irony of the disappearance of common-law marriage at a time when cohabitation is increasing-giving a new logic to the common-law principle. In other words, the theory of marriage itself is unfinished business.

His and hers. The nonadditive nature of marriage is an issue that is broader than the simple descriptive satisfaction level. Carroll et al. note that a feminist epistemology questions why women who do the majority of housework are still satisfied in their marriages. A Marxist might call this "false female consciousness." Thus the theory of marriage, gender, and division of labor is complex (see Sydie, 1987).

Marital power. Discussions of power in the family are confused both in their terminology and in their theory or explanation. Authority, influence, and decision making all contribute to the consideration of power. However, delegation is another issue that makes power more complex. If I delegate a task or decision because I don't want to be bothered with it, does that mean I have little or much power in that area? Obviously, I have power over who does it, but not over the outcome (Adams, 1995). Marital power and gender are, then, closely tied together empirically and theoretically.
Economics and marriage. Despite what W. J. Goode, H. Becker, and others have told us about the relations between the economy and marriage, changes in the economy continue to update the need for theory in this area. Rapid technological changes, which include both biotechnical developments and the increasingly "electronic cottage" (Toffler, 1980), leave us needing to develop more useful theory. And we still lack adequate theories of either consumerism or television and marriage.

Commuter marriages and LATs. The work of Jan Trost on marital relationships in which the couples are "living apart together" (LAT) has increased our cross-cultural understanding of such marriages. Coresidence can no longer be considered an essential characteristic of marriage. This, then, further complicates the first issue raised above-that is, What is marriage?

Marriage/divorce/happiness. Much value-laden ink has been spilled on the issue of whether divorce is a good or bad thing, a problem or a solution to a problem. Although no one has argued that divorce makes people happier, there is a still-open issue of whether divorce is better or worse than staying in a truly unhappy, conflict-filled marriage. And because of the ubiquity of value judgments, the development of theory concerning this issue has lagged.

These are enough points to raise in this commentary. This extension is meant to point out that it is insufficient simply to say, "We need to do more theorizing about marriage." Of course that is true. But there are many specific marital issues that deserve our theoretical attention, and they will require that we employ multiple philosophical perspectives and not presuppose a view of marriage as either stable or communication based. 


\section{REFERENCES}

Adams, B. N. (1995). The family: A sociological interpretation. Fort Worth, TX: Harcourt Brace Jovanovich.

Blaisure, K. R., \& Allen, K. R. (1995). Feminists and the ideology and practice of marital equality. Journal of Marriage and the Family, 57, 5-19.

Bodenmann, G. (1997). Dyadic coping: A systemic-transactional view of stress and coping among couples: Theory and empirical findings. European Review of Applied Psychology, 47, 137-141.

Boss, P. (2002). Family stress management: A contextual approach. Thousand Oaks, CA: Sage.

Bradbury, T. N., Cohan, C. L., \& Karney, B. R. (1998). Optimizing longitudinal research or understanding and preventing marital dysfunction. In T. N. Bradbury (Ed.), The developmental course of marital dysfunction (pp. 279-311). New York: Cambridge University Press.

Bradbury, T. N., Fincham, F. D., \& Beach, S. R. H. (2000). Research on the nature and determinants of marital satisfaction: A decade in review. Journal of Marriage and the Family, 62, 964-980.

Browning, D. S. (2003). Marriage and modernization. Grand Rapids, MI: William B. Eerdmans.

Browning, D. S., Conture, P. D., Franklin, R. M., Lyon, K. B., \& Miller-McLemore, B. J. (1997). From culture wars to common ground: Religion and the family debate. Louisville, KY: Westminster/John Knox.

Bulcroft, K., Bulcroft, R., Smeins, L., \& Cranage, H. (1997). The social construction of the North American honeymoon, 1880-1995. Journal of Family History, 22, 462-490.

Bulcroft, K., Smeins, L., \& Bulcroft, R. (1999). Romancing the honeymoon: Consummating marriage in modern society. Thousand Oaks, CA: Sage.

Bulcroft, R., Bulcroft, K., Bradley, K., \& Simpson, C. (2000). The management and production of risk in romantic relationships: A postmodern paradox. Journal of Family History, 25, 63-92.

Burleson, B. B., \& Denton, D. H. (1997). The relationship between communication skill and marital satisfaction: Some moderating effects. Journal of Marriage and the Family, 59, 884-902.

Burr, W. R., \& Klein, S. R. (1994). Reexamining family stress: New theory and research. Thousand Oaks, CA: Sage.

Cere, D. (2000). The expert's story of courtship. New York: Institute for American Values.

Coyne, J. C., \& Smith, D. A. (1991). Couples coping with a myocardial infarction: A contextual perspective on wives' distress. Journal of Personality and Social Psychology, 61, 404-412.

Cuber, J. F., \& Harroff, P. B. (1965). The significant Americans: A study of sexual behavior among the affluent. New York: AppletonCentury-Crofts.

Cusinato, M., \& L'Abate, L. (2003). The Dyadic Relationships Test: Creation and validation of a model-derived, visual-verbal instrument to evaluate couple relationships. American Journal of Family Therapy, 31, 79-89.

Doherty, W. J., \& Carroll, J. S. (2002). Health and the ethics of marital therapy and education. In J. Wall, D. S. Browning, W. J. Doherty, \& S. Post (Eds.), Marriage, health, and the professions: If marriage is good for you what does this mean for law, medicine, ministry, therapy, business? (pp. 208-232). Grand Rapids, MI: William B. Eerdmans.

Fay, B. (1996). Contemporary philosophy of social science: A multicultural approach. Oxford: Blackwell.

Fincham, F. D. (1998). Child development and marital relations. Child Development, 69, 543-574.

Fincham, F. D., \& Beach, S. R. H. (1999). Conflict in marriage: Implications for working with couples. Annual Review of Psychology, 50, 47-77.

Fincham, F. D., Beach, S. R. H., \& Kemp-Fincham, S. I. (1997). Marital quality: A new theoretical perspective. In R. J. Sternberg \& M. Hojjat (Eds.), Satisfaction in close relationships (pp. 275-304). New York: Guilford.

Fincham, F. D., \& Bradbury, T. N. (1987). The assessment of marital quality: A reevaluation. Journal of Marriage and the Family, 49, 797-809.

Fincham, F. D., \& Linfield, K. J. (1997). A new look at marital quality: Can spouses feel positive and negative about their marriage? Journal of Family Psychology, 11, 489-502. 
Fowers, B. J. (2000). Beyond the myth of marital happiness. San Francisco: Jossey-Bass.

Fox, G. L., \& Murry, V. M. (2000). Gender and families: Feminist perspectives and family research. Journal of Marriage and the Family, 62, 1160-1172.

Gottman, J. M. (1982). Temporal form: Toward a new language for describing relationships. Journal of Marriage and the Family, 44, 943-961.

Gottman, J. M. (1999). The marriage clinic: A scientifically based marital therapy. New York: W. W. Norton.

Gottman, J. M., \& Notarius, C. I. (2000). Decade review: Observing marital interaction. Journal of Marriage and the Family, 62, 927-947.

Gough, E. K. (1959). The Nayar and the definition of marriage. Journal of the Royal Anthropological Institute, 89, pt. 1.

Guba, E. G., \& Lincoln, Y. S. (1994). Competing paradigms in qualitative research. In N. K. Denzin \& Y. S. Lincoln (Eds.), Handbook of qualitative research (pp. 105-117). Thousand Oaks, CA: Sage.

Hechter, M. (1987). Principles of group solidarity. Berkeley: University of California Press.

Hill, R. (1949). Families under stress. New York: Harper.

Holman, T. B. (2001). Premarital prediction of marital quality or breakup: Research, theory, and practice. New York: Kluwer Academic/ Plenum.

Homans, G. (1970). The relevance of psychology to the explanation of social phenomena. In R. Borger \& F. Cioffi (Eds.), Explanation in the behavioural sciences (pp. 313-329). Cambridge: Cambridge University Press.

Kantor, D., \& Lehr, W. (1975). Inside the family: Toward a theory of family process. San Francisco: Jossey-Bass.

Karney, B. R., \& Bradbury, T. N. (1995). The longitudinal course of marital quality and stability: A review of theory, method, and research. Psychological Bulletin, 118, 3-34.

Kerckhoff, A. (1974). The social context of interpersonal attraction. In T. L. Huston (Ed.), Foundations of interpersonal attraction. New York: Academic Press.

Kluwer, E. S. (2000). Marital quality. In R. M. Milardo \& S. Duck (Eds.), Families as relationships (pp. 59-78). New York: John Wiley.
Knapp, S. J. (2002). Authorizing family science: An analysis of the objectifying practices of family science discourse. Journal of Marriage and Family, 64, 1038-1048.

L'Abate, L. (1986). Systematic family therapy. New York: Brunner/Mazel.

L'Abate, L. (2003). Family psychology III: Theorybuilding, theory-testing and psychological interventions. Lanham, MD: University Press of America.

L'Abate, L. (in press). Personality in intimate relationships: Socialization and psychopathology. New York: Kluwer Academic.

L'Abate, L., \& De Giacomo, P. (2003). Intimate relationships and how to improve them: Integration of theoretical models with prevention and psychotherapy interventions. Westport, CT: Praeger.

Larson, R. W., \& Almeida, D. M. (1999). Emotional transmission in the daily lives of families: A new paradigm for studying family process. Journal of Marriage and the Family, 61, 5-20.

Lavee, Y., \& Gilat, A. (2000, November). Distance regulation in couples under daily stresses and strains. Paper presented at the 62nd Annual Meeting of the National Council on Family Relations, Minneapolis.

Lavee, Y., \& Mey-Dan, M. (2003). Patterns of change in marital relationships among parents of children with cancer. Health and Social Work, 28, 255-263.

Lincoln, Y. S., \& Guba, E. G. (2000). Paradigmatic controversies, contradictions, and emerging confluences. In N. K. Denzin \& Y. S. Lincoln (Eds.), Handbook of qualitative research (2nd ed., pp. 163-188). Thousand Oaks, CA: Sage.

Loveless, A. S. (2000). Paired conceptions of morality and happiness as factors in marital happiness. Unpublished doctoral dissertation, Brigham Young University, Provo, UT.

Markman, H. J., Notarius, C. I., Stephen, Y., \& Smith, T. (1981). Behavioral observation systems for couples: The current status. In E. E. Filsinger \& R. A. Lewis (Eds.), Assessing marriage: New behavioral approaches (pp. 234-262). Beverly Hills, CA: Sage.

McCubbin, H. I., \& Patterson, J. M. (1983). The family stress process: The double ABCX model of adjustment and adaptation. In H. I. McCubbin, M. B. Sussman, \& J. M. Patterson (Eds.), Social stress and the family: Advances 
and developments in family stress theory and research (pp. 7-37). New York: Haworth.

Peggs, K., \& Lampard, R. (2000). (Ir)rational choice: A multidimensional approach to choice and constraint in decisions about marriage, divorce and remarriage. In M. S. Archer \& J. Q. Tritter (Eds.), Rational choice theory: A critique (pp. 93-110). New York: Routledge.

Procter, I. (2000). "I do": A theoretical critique of Becker's rational choice approach to marriage decisions. In M. S. Archer \& J. Q. Tritter (Eds.), Rational choice theory: A critique (pp. 147-166). New York: Routledge.

Raudenbush, S. W., \& Bryk, A. S. (2002). Hierarchical linear models: Applications and data analysis methods (2nd ed.). Thousand Oaks, CA: Sage.

Regan, M. C., Jr. (1993). Family law and the pursuit of intimacy. New York: New York University Press.

Rigney, D. (2001). The metaphorical society: An invitation to social theory. New York: Rowman \& Littlefield.

Root, M. (1993). Philosophy of social science: The methods, ideals, and politics of social inquiry. Oxford: Blackwell.

Slife, B. D., \& Williams, R. N. (1995). What's behind the research: Discovering hidden assumptions in the behavioral sciences. Thousand Oaks, CA: Sage.
Stanley, S. (1998). The heart of commitment. Nashville, TN: Nelson.

Sydie, R. A. (1987). Natural women, cultured men: A feminist perspective on sociological theory. Toronto: Methuen.

Thibaut, J. W., \& Kelley, H. H. (1959). The social psychology of groups. New York: John Wiley.

Thomas, D. L., \& Wilcox, J. E. (1987). The rise of family theory: A historical and critical analysis. In M. B. Sussman \& S. K. Steinmetz (Eds.), Handbook of marriage and the family (pp. 81-102). New York: Plenum.

Thompson, L. (1993). Conceptualizing gender in marriage: The case of marital care. Journal of Marriage and the Family, 55, 557-569.

Toffler, A. (1980). The third wave. New York: William Morrow.

Udehn, L. (2002). The changing face of methodological individualism. Annual Review of Sociology, 28, 479-507.

Watzlawick, P., Weakland, J. H., \& Fisch, R. (1974). Change: Principles of problem formation and problem resolution. New York: W. W. Norton.

White, J. M., \& Klein, D. M. (2002). Family theories (2nd ed.). Thousand Oaks, CA: Sage.

Wood, J. T. (1995). Feminist scholarship and the study of relationships. Journal of Social and Personal Relationships, 12, 103-120. 